Building performance and end-user interaction in passive solar and low energy housing developments in Scotland

Tim Sharpe ${ }^{a^{*}}$, Gráinne McGill ${ }^{a}$, Rosalie Menon ${ }^{a}$, Paul Farren $^{b}$

${ }^{a}$ Mackintosh Environmental Architecture Research Unit, Glasgow School of Art, Glasgow, UK

${ }^{b}$ Architecture Department, University of Strathclyde, Glasgow, UK

*corresponding author: t.sharpe@gsa.ac.uk, +44 (0) 1413534658 


\section{Building performance and end-user interaction in passive solar and low energy housing developments in Scotland}

In the UK housing sector, changes to building regulations have raised standards for fabric performance, bringing about a demand for affordable, low energy housing. Housing Associations have been at the forefront of adopting these measures, but as owners of long term rented stock it is important for them to understand and evaluate the performance of both 'as-built' and 'as-occupied' dwellings. This paper describes a detailed evaluation of three new-build social housing demonstration projects located in Glasgow (Scotland). The study included occupant surveys in each scheme, fabric testing and detailed monitoring of environmental conditions, energy consumption, and evaluation of occupancy behaviours in eight dwellings. A particular focus of this paper is the ventilation performance as the homes are ventilated differently using natural, mechanical extract and mechanical heat recovery methods. The results showed a wide discrepancy of energy consumption and poor levels of ventilation, particularly in bedrooms. Causes of this included the design and installation of the ventilation provision but occupant interaction with the systems was also a significant factor. Two sites included sun-spaces that, despite having good potential for preheat ventilation and drying spaces, were underperforming. The study highlights significant impacts of the complex interactions between heating and ventilation systems, and the apparent need for more effective ventilation strategies and systems in bedroom spaces, but also improved strategies for end-user understanding of, and interaction with, both mechanical systems and natural ventilation opportunities. The papers aims to provide robust and credible evidence on which to base critical regulatory and design decisions on the most effective means of ventilating low carbon social housing in Britain.

Keywords: social housing, building users, ventilation, performance evaluation, sun space

\section{Introduction}

Changes in building regulations, driven in part by climate change policies have raised standards for thermal performance in new housing in the UK. This has led to improved thermal standards and energy efficiency and increased use of low carbon technologies. 
Housing associations have taken an active role in developing new approaches to the design and construction of housing in their stock. An example of this was the "Glasgow House", developed by Glasgow Housing Association (GHA) as a model of low energy, flexible, affordable housing that would be a solution for both social and private rented sectors, and housing for sale. A prototype was built and tested in a Building Performance Evaluation (BPE) programme commenced in 2011, the outcomes of which have been reported previously (Sharpe and Shearer, 2014). The knowledge gained in the prototype project was used to inform the subsequent real-world iteration of the test house in new types of homes constructed in 2014. This paper describes a further BPE study on these completed dwellings which included two versions of the design, Case study A (CS-A) and Case Study B (CS-B), and additionally a comparable low energy housing project constructed at the same time, Case study $\mathrm{C}(\mathrm{CS}-\mathrm{C})$. The intention was to determine how well these buildings performed with real world occupancy, to identify technical issues and to evaluate how occupants interacted with these homes. The particular focus of this paper is the ventilation performance. The original Glasgow House prototype had included sunspaces and a Mechanical Ventilation with Heat Recovery (MVHR) system, but associated problems had led the client to omit the MVHR in its subsequent iterations. The as-built ventilation provision included:

- CS-A with passive stack ventilation (PSV) and humidity controlled trickle vents

- CS-B with a decentralised mechanical extract ventilation system (dMEV) with conventional trickle vents

- CS-C with MVHR

\section{Project Information}


[Insert] Figure 1. CS-A: Carntyne, Glasgow (55.9 Latitude, 4.2 Longitude)

CS-A contains a hundred new-build homes completed in 2014, including a mix of two, three and four bedroom houses and flats. The development includes eight low energy homes with sunspaces that were included in the study. Construction is timber frame with a rendered brick outer skin.

[Insert] Figure 2. CS-B: Castlemilk, Glasgow (55.8 Latitude, 4.2 Longitude)

CS-B includes thirty-two new-build homes (constructed in 2014), made up of twentyeight semi-detached houses (with sunspaces) and four flats. The homes are both midmarket rented and purchased with shared equity ownership. They were constructed in timber frame with a facing brick outer skin.

[Insert] Figure 3. CS-C: Springburn, Glasgow (55.9 Latitude, 4.2 Longitude)

CS-C comprises forty-nine low energy flats (one, two and three bedrooms), contained in five blocks. The homes were constructed in 2014 with a closed panel timber frame system with an external metal rain screen cladding.

[Insert] Figure 4. Floor plans and monitoring locations of dwellings at CS-A and CS-B Sensor locations

[Insert] Figure 5. Floor plans and monitoring locations of dwellings at CS-C Sensor locations

[Insert] Table 1. Dwelling characteristics 


\section{Sunspace design}

The sunspaces were a key part of the original prototype and were retained in both CS-A and CS-B. The use of sunspaces in Glasgow have long been established as a useful contribution to energy reductions (Porteous 1997; Shearer and Porteous, 2012), principally as a means to preheat fresh air. They are constructed of a double-glazed metal insulated frame system, with a double-glazed door and single side-opening window at upper level. The tiled flooring at the lower levels provides some thermal mass. A simple open joint timber decking at upper levels enables warm air from below to travel by natural convection to the space above (adjacent to the bedroom area). The wall between the building and the sunspace is a simple timber studwork faced on both sides with lightweight plasterboard, rather than a continuation of the external facing brick or render used elsewhere on the building.

In CS-A, the sunspaces are at the rear of the building, connected to the kitchen and bedroom spaces at lower and upper levels respectively and face south (PS1A) and south-west (PS2A). In CS-B, the sunspaces are located to the front of the house and connect with the living room at the lower level and the bedroom at the upper level and face south (ME1B) and east (ME2B). This spatial relationship between rooms may affect patterns of use and levels of potential moisture migration into each sunspace. Moreover, the differences in sunspace orientation will have a significant impact on the overall year round effectiveness of this space.

External air supply to the sun spaces is provided via patio doors and a single first-floor window, as illustrated in Figure 6. External trickle vents are also installed at site CS-B. Movement of air from the sunspace into the dwelling is also via trickle vents above the internal doors in site CS-B, but at site CS-A ventilation of the sunspaces is reliant solely on occupant behaviour in the form of opening doors and/or windows. 
[Insert] Figure 6. Air supply to sunspaces at Sites CS-A \& CS-B

\section{Methodology}

The three case studies employed a uniform methodology using both qualitative and quantitative methods producing multiple data sets, including occupant feedback, environmental monitoring and fabric and ventilation performance testing data. A realworld approach was employed by examining performance 'as-built' and 'as-occupied', providing the opportunity to evaluate the impact of the end-user on overall performance in a real-life context.

\section{Household survey}

An initial large-scale door-to-door survey was undertaken at the three sites using a short questionnaire to gain information on occupant behaviour, perception of indoor environmental quality and awareness and use of ventilation in the home. Information was gained from sixty-three households:

- Twenty-seven households at Site CS-A \& CS-B - a response rate of 75\%

- Thirty-six households at Site C, a response rate of $73 \%$

Eight households were selected for detailed monitoring (Table 1), based on willingness to participate, representativeness and availability.

\section{Ventilation performance evaluation}

Airflow rate measurements were carried out using an Observator air volume flow meter, to measure extract rates in dwellings with Mechanical Extract and Passive Stack ventilation, and supply and extract rates under trickle and boost conditions in homes with MVHR. Where present, filters were inspected and photographed before the airflow 
measurements. The heat recovery efficiency of the MVHR system was monitored insitu in one dwelling at CS-C (MV2C). Eltek GD34 temperature thermistors were inserted in the four flows (extract, exhaust, outdoor and supply air vents) and the heat recovery efficiency was calculated on both the supply and exhaust side. Sound measurements were performed in one dwelling at CS-B (ME1B) and one dwelling at CS-C (MV2C), following complaints of noise from the ventilation system.

Measurements were taken in various rooms with the ventilation system off, on normal and on boost mode (MV2C only), using Pulsar Real Time Analyzer Model 30.

Comparisons are made with the requirements of the current Scottish Building Standards technical guidance, to which the houses would be required to comply. Levels of $\mathrm{CO}_{2}$ is used as an appropriate indicator to measure IAQ. Whilst concentrations of $\mathrm{CO}_{2}$ are very rarely found at hazardous levels indoors, it keeps bad company (Porteous 2011) and increased levels of $\mathrm{CO}_{2}$ are indicative of occupancy and inadequate ventilation. CIBSE Guide A (CIBSE 2006) categorises indoor air quality at moderate or poor over 1150 ppm and levels above 1000 ppm are linked to poor occupant health (Wargocki 2013).

\section{Seasonal analysis}

Monitoring was undertaken in all eight case study dwellings, which consisted of i) indoor environmental monitoring (Eltek IAQ data loggers), ii) energy meter readings, iii) occupant diary, iv) interviews with occupants, v) a practical exercise, and vi) a photographic survey.

Temperature, relative humidity and carbon dioxide $\left(\mathrm{CO}_{2}\right)$ levels were monitored in the main bedroom, living room and kitchen of the selected dwellings for three weeks between March - April and August - September 2016, with simultaneous measurements of external conditions. Monitoring equipment was positioned in accordance with ISO: 16000:1. Environmental data was collected at 5-minute intervals. Energy meter readings 
were taken during the summer and spring/winter site visits to gain information on electric and gas consumption. Extrapolations were made using heating degree days for Glasgow to estimate the annual energy consumption of each home based on the recorded data (CS-A\&B: March - September 2016; CS-B: January - March 2016). In addition, occupants were asked to complete an occupant diary which captured information on daily occupancy levels, heating schedules and activities during the monitoring period.

Semi-structured occupant interviews were carried out in all monitored dwellings to gain information on occupant perceptions, behaviours, interactions and use of the home. This was supplemented by a practical exercise, to help identify the level of occupant understanding and awareness of ventilation, heating and hot water systems.

\section{Fabric performance testing}

Performance testing of the building fabric was conducted in selected dwellings during the winter/spring season. Air permeability tests were undertaken in all four monitored dwellings at Site A \& B and one monitored dwelling at site C (MV2C) in accordance with ATTMA TSL1- Issue 1, using an air depressurisation and pressurisation technique (Retrotec 3000 blower door fan set). Tests were performed with internal sunroom doors open and closed. A walk around of each room was undertaken during the airtightness testing with a smoke pencil, to locate any areas of air flow into the building. Internal and external thermography surveys were also carried out (using Thermo Tracer TH9260), to identify air leakage paths, condensation risk or water damage, and the continuity and performance of insulation. U-value tests were performed on a wall and roof section in one dwelling at Site A (PS1A) and one dwelling at Site C (MV3C), using Eltek GS44H and Hukseflux HFP01 heat flux sensors. 


\section{Results}

\section{Household survey}

The household survey revealed a lack of occupant awareness and understanding of the ventilation strategies in both mechanically ventilated and naturally ventilated dwellings. In homes with dMEV and passive stack ventilation (CS-A \& B), windows were fitted with trickle vents, but only $56 \%$ of households were aware of the presence of these and $26 \%$ stated that they were not present. Of those aware of the presence of trickle vents, $27 \%$ stated that these were never used for background ventilation.

At CS-C (MVHR homes), all households were aware of the presence of the ventilation system, but there appeared to be a general lack of understanding regarding how the system was controlled, with $39 \%$ unaware of the presence of boost switches in their home. Of those aware of these switches, 55\% stated that they were never used. Nevertheless, $82 \%$ of households at CS-A \& B and $64 \%$ of households at CS-C indicated that they were shown how to ventilate their home during the handover process. Overall, $89 \%$ of households at CS-C stated that they never had any issues with the MVHR system. Issues that were reported included the build-up or 'creation' of dust $(6 \%)$, discolouration (of supply or extract grilles) $(3 \%)$ or faults with the ventilation system $(3 \%)$.

\section{Fabric performance}

The air permeability for the main house volume in CS-A and B ranged between 4.76 and $5.99 \mathrm{~m}^{3} / \mathrm{h} / \mathrm{m}^{2} @ 50 \mathrm{~Pa}$. However if the sunspace was included these varied between 7.1 and $14.5 \mathrm{~m}^{3} / \mathrm{h} / \mathrm{m}^{2} @ 50 \mathrm{~Pa}$. These figures are reasonable, in that conceptually the sunspaces should not be considered part of the heated or occupied volume but do indicate the increased air permeability of sunspaces and smoke pencil testing showed 
leaks around the steel frame structure and there were some issues of water penetration in these spaces.

In contrast, the airtightness of the tested house at CS-C was $11.3 \mathrm{~m}^{3} / \mathrm{h} / \mathrm{m}^{2} @ 50$ $\mathrm{Pa}$, equivalent to $14.38 \mathrm{ach}$. This was well above the accepted threshold of 3-5 ach for MVHR systems. Smoke testing identified numerous air leakage paths, the most significant being under the kitchen units and washing machine, around the MVHR unit, around the bath panel and at the open pipe chase at the side of the toilet.

Measured wall U-values in the monitored dwellings were close to design values with the exception of a roof section in one home which was $0.26 \mathrm{~W} / \mathrm{m}^{2} \mathrm{~K}$, much higher than the design value of $0.15 \mathrm{~W} / \mathrm{m}^{2} \mathrm{~K}$.

\section{Ventilation performance}

Inspections at CS-B identified that dMEV systems in the downstairs toilet, kitchen and upstairs bathroom of both properties had been turned off by the building occupants (during either spring or summer site visits) using the local isolator switch, which is likely to result in reduced ventilation. It should be noted that this switch is provided to allow maintenance of the unit, rather than a means of control. The main reason given for this was problems with noise from the fans and this was supported by the results of sound measurements, where levels exceeded $35 \mathrm{~dB}$ LAeq with the MEV system in operation. In addition, half of the trickle vents were found to be in the closed position.

[Insert] Figure 7. Measured ventilation levels in air changes per hour (ACR) and litres per second per person $(1 / \mathrm{s} / \mathrm{p})$

[Insert] Figure 8. Bedroom carbon dioxide levels

[Insert] Figure 9. Living room carbon dioxide levels 
[Insert] Figure 10. Carbon dioxide levels in PS1A

[Insert] Table 2: Measured extract rates in dwellings with Passive Stack (PS) and Mechanical Extract Ventilation (ME)

[Insert] Table 3: Measured supply and extract rates in dwellings with Mechanical Ventilation with Heat Recovery

The flow testing revealed inadequate ventilation provision in the majority of homes. For instance, in the four homes with MVHR systems at CS-C, measured flow rates did not meet design targets under normal operation. In two of these flats, a significant imbalance $(>50 \%)$ was identified between supply and extract rates, favouring extract (see Table 3) which would result in additional cold air being drawn into the home in winter. In one home (MV2C), detailed inspection revealed that the living room supply vent had been closed tight by the building occupants during the winter months, due to complaints of draughts.

Measurements of extract rates in two homes with PSV at CS-A suggest low levels of ventilation $(0.22-0.23 \mathrm{ach})$, however it should be noted that these results are dependent on external conditions at the time of measurements. At CS-B, although measured extract rates of the systems in the two homes with dMEV met the guidance for Scottish Building Regulations (Table 2), ventilation rates are likely to be inadequate given that most of these systems had been deactivated by building occupants.

Figures 7-10 present the results of physical measurements of ventilation performance in the eight case study homes. As illustrated, only one dwelling (ME2B) satisfied ventilation guidelines of both $>0.5$ ach and $>81 / \mathrm{s} / \mathrm{p}$. However, ventilation measurements in this home were taken when the dMEV systems were in operation, which was not representative of normal conditions. In four of the monitored dwellings, 
although ventilation rates greater than $81 / \mathrm{s} / \mathrm{p}$ were measured, air change rates below the recommended 0.5 ach were found.

$\mathrm{CO}_{2}$ levels peaked above $1,000 \mathrm{ppm}$ in all monitored living rooms and main bedrooms during winter/spring seasons. Average bedroom $\mathrm{CO}_{2}$ levels exceeded 1,000 ppm in the two dwellings with Passive Stack Ventilation. As illustrated in Figure 10, bedroom $\mathrm{CO}_{2}$ levels were consistently high overnight in PSA1, suggesting inadequate night-time ventilation in bedrooms.

\section{Energy consumption}

Variations of energy consumption observed in dwellings of comparable construction, orientation and size demonstrates the significant impact of occupant behaviour on energy performance in practice. For example, despite being identical with regards to design and construction, annual gas consumption differentiated by a factor of 4.3 between PS1A and PS2A, a factor of 1.3 between ME1B and ME2B, and a factor of 3.2 between MV2C and MV4C. Electrical consumption was more consistent; with the greatest variation identified between ME1B and ME2B (by a factor of 1.7).

[Insert] Figure 11. Annual Energy Consumption

*Extrapolated from measured data

\section{Indoor environmental quality}

Mean temperatures ranged from $17-23^{\circ} \mathrm{C}$ during the winter / spring monitoring and 19 $-26^{\circ} \mathrm{C}$ during summer monitoring, as illustrated in Table 4. Incidences of overheating were observed during all monitored seasons. For example, in home PS2A, peak temperatures in the main bedroom adjacent to the sunspace reached $48^{\circ} \mathrm{C}$ at $16: 50$ on the $20^{\text {th }}$ April (outside temperature $20^{\circ} \mathrm{C}$ at this time). The south-west orientation of the sunspace in this home is likely to have attributed to these high readings. 
Cooler temperatures were also observed during the winter and spring seasons, with temperatures dropping to 10 or $11^{\circ} \mathrm{C}$ in some homes. Lowest mean temperatures were observed in MV2C, which corresponds to the findings from the household interviews as occupants expressed particular issues with thermal comfort in this home (likely attributed to the poor levels of airtightness). The occupants explained that they normally use an electric heater to heat the main bedroom before they go to bed, which was evident by the short peaks in temperature observed at night (Figure 12).

[Insert] Table 4. Indoor Environmental Conditions in monitored rooms

Similarly, in MV1C, occupants stated that the living room can get quite cold, which they attributed to the radiator being positioned near the door and away from the centre of the room. Nevertheless, occupants explained that they used an electric heater in the living room during winter to maintain comfortable conditions. Winter temperatures peaked at $30^{\circ} \mathrm{C}$ in the living room of this home. In six out of the eight houses, average bedroom temperatures in the winter/spring were the same or higher than living room temperatures.

[Insert] Figure 12. Weekly temperature in February (MV2C)

Measured relative humidity levels were generally within acceptable limits (30-60\%); however, peaks above $70 \%$ were observed in seven monitored rooms during spring / winter and nineteen monitored rooms during summer. Summer average levels exceeded $60 \%$ in eight rooms. Humidity levels in spring fell below $20 \%$ in two bedrooms adjacent to the sunspace (PS2A \& ME1B). The very high temperatures observed mean that actual moisture levels in the home may be significant. 


\section{Sunspace performance}

Significantly high peak levels of relative humidity and temperature were observed in the downstairs and upstairs sunspace in all four dwellings during spring and summer monitoring. Sunspace relative humidity levels regularly exceeded $70 \%$. The household survey revealed that $44 \%$ of households (in CS-A \& B) reported the presence of mould, mildew or condensation on walls or surfaces in their home; the majority of these in the sunspace $(92 \%)$. This may be attributed in part to the high reported frequency of drying clothes in the home (93\%), with a quarter of all respondents stated that they use the sunspace for drying clothes.

[Insert] Table 5. Comparison of indoor conditions in sunspace with adjacent rooms

As illustrated in Table 5, peak temperatures in the sunspace frequently exceeded those of the adjacent spaces. Whilst this indicates the availability of 'free' heating, some of the building characteristics mitigate against the effective use of this. The lack of thermal mass in these spaces means that peaks are high - maximum sunspace temperatures exceeded $50^{\circ} \mathrm{C}$ during both spring and summer monitoring periods - and heat retention is reduced. There is not a clear strategy for distribution of heat to the remainder of the house due to the limited air pathways between the sunspace and the heated interior and the reliance on appropriate end-user interaction in the form of selectively opening and/or closing internal and external doors (and windows) to the sunspace at suitable times of the day, depending on the conditions. As a result, temperatures in directly adjacent rooms, particularly the bedroom were very high; $19 \%$ of households reported having experienced problems with overheating indoors, which were mainly attributed to the sunroom, particularly in the upstairs sunspace adjoining the bedroom. 


\section{Discussion}

This study sought to identify the degree (if any) of ventilation and environmental performance gaps, determine possible causes of these gaps and to gain a greater level of understanding of the impact of the end-user on overall building and environmental performance.

\section{Ventilation and end-user interaction}

The results from the household survey suggest a lack of understanding of the ventilation provision by the occupants. Despite having received advice about ventilation, they were not clear about the operation and purpose of MVHR systems, lacked awareness of trickle vents and were confused between passive and mechanical ventilation strategies. These findings are supported by the results of the monitoring, which found dMEV systems had been turned off due to complaints of noise and many adjustable trickle vents had been closed by the building occupants. Automatic humidity-sensitive trickle vents were installed in the homes with PSV, which could not be adjusted by the building occupants. Although there was no evidence of MVHR systems being deactivated in the monitored flats at CS-C, occupants were able to adjust the supply vents and, in some cases, had done so to adjust thermal comfort (perceived cold air coming in above a bed). Households reported a high frequency of window opening, particularly during the summer season. Homes with PSV and dMEV reported a higher frequency of window opening than those with MVHR systems.

The impacts of occupants closing supply vents, turning off dMEV systems or closing trickle vents were observed in the monitoring, which found consistently poor ventilation (evidenced by high levels of $\mathrm{CO}_{2}$ and low measured air change rates) in the case study dwellings. 
Whilst occupant interaction with ventilation provision is frequently characterised as 'misuse', it was also apparent that there was a lack of understanding of ventilation strategies by designers and clients. In this study there were no clear benefits identified in CS-A, where systems were less susceptible to occupant intervention.

It would appear that strategies for control were 'specified' rather than 'designed'. Some characteristics of systems were not clearly considered, for example air flow rates, vent placement and acoustic nuisance, and these were compounded by defects in installation and commissioning.

Bedroom spaces are particularly problematic. Opportunities for adaptive behaviour such as opening windows are limited as occupants are asleep, and thus ventilation provision is reliant on whatever strategy is in place when they go to bed. High night-time bedroom $\mathrm{CO}_{2}$ levels indicative of poor ventilation rates were commonplace and replicate previous studies that identified significant issues with bedroom ventilation provision (Bekö et al, 2010; McGill et al, 2015; Sharpe et al, 2014).

The premise that modern airtight homes with MVHR systems must necessarily be better ventilated than those ventilated naturally given the ability of MVHR systems (in theory) to provide a continuous supply of air to a building was examined in this study. The fact that in CS-C better advice to occupants seems to have resulted in MVHR systems not being deactivated at an early stage is a step in the right direction and the bedroom $\mathrm{CO}_{2}$ levels were generally lower in monitored homes with MVHR systems. However, one dwelling (MV4C) was a notable exception and this highlights the potential risk of poor ventilation in homes dependent on MVHR. The findings also need to be contextualised by the poor measured airtightness (in MV2C) and lower levels of occupancy (MV2A, MV2B, MV2C) which may have influenced the results. 
However, the application of MVHR systems in new-build dwellings represents a step change in domestic ventilation practices and as such, requires careful consideration to ensure effective design, installation, performance, maintenance and operation, particularly in a social housing context. Therefore, the reliance of the dwelling on a constantly running system remains a high-risk strategy due to concerns not only about the costs to occupants but also the longevity of systems and components, the degree of occupancy control (and resulting satisfaction), the complexity, responsiveness and transparency of systems, and the need to reduce carbon emissions (despite increasing mechanisation of buildings). These challenges need to be addressed to ensure effective, efficient, user-friendly and environmentally responsive ventilation solutions for contemporary housing. This also raises questions about the economic effectiveness and affordability of such systems (Jenkins, 2010).

\section{Sunspace performance}

It is clear that the sunspaces are capable of generating useful heat if orientated and located appropriately (i.e. outwith the heated envelope). Their use may assist with other aspects of the operation of the building for example to remove internal clothes drying from occupied rooms and to preheat ventilation air.

However, in these dwellings the effectiveness of this is undermined: firstly, by the lack of thermal mass in the spaces; secondly by an inability to effectively distribute the heat throughout the building; and thirdly by the reliance on occupant interventions to manage the space.

At present there is a (not unreasonable) tendency to leave clothes in spaces overnight, but the temperature can drop significantly, and surface condensation and ultimately black mould can occur, particularly on the metal frames. With additional mass, the peak temperatures are reduced and both air and surface temperatures would be 
warmer and so the impacts of clothes drying overnight would also be reduced. A brick surface may also be less susceptible to mould growth.

The effectiveness of the sunspaces for ventilation pre-heat of air in the monitored homes relies predominantly on occupant intervention in the form of controlling ventilation from the sunspaces to habitable rooms and from the sunspace to outdoors. As demonstrated in a previous study, the amount and frequency of window opening to buffer spaces is largely dictated by specific occupancy and social characteristics in addition to seasonal influences (Porteous and Ho, 1997). If the home is unoccupied during the day and ventilation of the sunspace is limited, particularly if occupants are reluctant to leave windows open whist the house is unoccupied, there is potential for heat to build up in this space. To provide passive natural ventilation between the sunspace and adjacent habitable rooms, vents at upper and lower levels are required, to allow for convection and to pull cooler air from the room into the sunspace.

An alternative would be to mechanically assist the movement of pre-warmed air to other parts of the house. This has been demonstrated to be a useful strategy in a similar contemporary building in Scotland (Currie, Capper and Holmes, 2006) which indicates that a sunspace can save up to $15 \%$ of the domestic heating requirements when compared with traditional infiltration ventilation, and more than double the energy benefit of that obtained by positive input only ventilation. The effectiveness of this needs to be tempered by the issues encountered with mechanical systems in terms of provision, commissioning and occupant interaction.

The nature of the space is such that there will inevitably be occupant interaction with the sunspace. To be more effective, better provision for ventilation is required (for example trickle vents between the sunspace and occupied rooms) and improved advice for effective strategies, which may include different modes in different seasons - for 
example, more liberal sunspace opening in summer, optimal opening use when unoccupied during the day, and use for clothes drying.

\section{Conclusion}

Overall the study highlights that there is still an incomplete understanding of the issues of ventilation and energy use in contemporary low energy dwellings. Improved regulatory requirements for thermal standards have led to improvements in some aspects of environmental provision, such as improved U-values and airtightness, and adoption of some low energy technologies. Housing associations have been at the forefront of the adoption of these, but at present the solutions tend to be piecemeal and driven by (theoretical) compliance with guidance to Building Regulations and with the exception of projects like these, there is little routine assessment of actual performance.

These dwellings represent important steps in the right direction in a number of ways, but with some important caveats. Firstly, the use of BPE is a vital aspect of the generation of knowledge about the performance of such systems, and the iterations in CS-A and B did draw on previous studies. However in these dwellings some key strategies were not implemented. These include the need for thermal mass to control temperature in the sunspace and the lack of integrated ventilation strategies (either to move warm air into the home, or to purge moisture air). Clearly, mechanisms to improve feedback loops need to be strengthened. Nevertheless, the study has contributed to real-world knowledge and is being used to inform future iterations for a major housing association.

Secondly, whilst there was some evidence of improved user guidance and knowledge on the operation of the systems, further work is needed here, both to improve the provision (e.g. clear and intuitive controls, quieter systems, locking vents, improved placement of vents), but also occupant guidance on the use of the system. 
Design needs to address not just the physical form of the building, but how it should be used.

For this to be effective there is a need for improved understanding at design stages. In contemporary construction it would seem that design effort has become directed toward the achievement of regulatory compliance, rather than any comprehensive understanding of aspects of architectural science that would inform how a building might work and perform. With improved thermal standards, the holistic effects and interactions between the building fabric, heating and ventilation systems, and building occupants become critical and need to be considered in greater depth.

It would also seem that aspects of the regulatory process need re-evaluation. Firstly, the separation of intrinsically linked aspects such as heating, thermal performance, ventilation and air quality into different sections of the building regulations, and possible compromise by others (for example fire regulations requiring fire doors and flame-retardant coatings) limits the ability for designers and clients to identify comprehensive solutions. Secondly, it seems clear that architects are conflating guidance (which identifies solutions that are deemed to satisfy the regulations) with the regulations themselves. This position tends to be reinforced by building control departments who are unable or unwilling to accept alternative verification. It is suggested that this may be a downward spiral - emphasis by regulation on compliance with guidance means that designers do not design from first principles, as a result of which the need for this technical knowledge has been lost. Design practice is therefore increasingly detached from a research and technical knowledge base.

Thirdly, the majority of compliance happens at design stages and there is increasingly little inspection and testing on site. It is perhaps ironic that the only example of on-site verification is air permeability testing, which has clearly raised standards, but the findings of this study identify that this is not perfect. There is very 
little verification of ventilation provision, such as commissioning or monitoring. This also undermines the relationships between design and construction.

Finally, the construction industry does not as a matter of routine examine the performance of its buildings. Studies such as these are not commonplace and routes for communication of research knowledge into the profession are limited. Thus the knowledge which may inform all of the above processes is absent.

\section{References}

ATTMA TSL1- Issue 1 (2016) - Technical Standard L1, Measuring air permeability in the envelopes of dwellings, The Airtightness Testing \& Measurement Association

Bekö G, Lund T, Nors F, Toftum J and Clausen G (2010) Ventilation rates in the bedrooms of 500 Danish children. Build Environ 45(10): 2289-2295.

CIBSE 2006. Chartered Institute of Building Service Engineers (CIBSE), CIBSE Guide A: Environmental Design, 2006, ISBN-13 9781903287668

Currie J, Capper G, Holmes J, (2006), Energy efficiency improvements through sunspace augmented positive input ventilation of buildings, In EPIC 2006, 20$22^{\text {nd }}$ November 2016, Lyon

ISO: 16000:1 (2004), Indoor air - Part 1: General aspects of sampling, International Organisation for Standardisation

Jenkins, D,P., 2010, The value of retrofitting carbon-saving measures into fuel poor social housing, Energy Policy, 38(2): 832-839

McGill G, Oyedele L, Keeffe G, et al. (2015) Bedroom Environmental Conditions in Airtight Mechanically Ventilated Dwellings. Eindhoven: ISIAQ. 
Porteous, C. D. A., \& Ho, H. M. (1997). Do sunspaces work in Scotland? Lessons learnt from a CEC solar energy demonstration project in Glasgow. International journal of ambient energy, 18(1), 23-35.

Porteous, C. (2011). Sensing a historic low-CO2 future. In Chemistry, Emission Control, Radioactive Pollution and Indoor Air Quality. InTech.

Sharpe T, Sheerer D, (2014), Scenario testing of the energy and environmental performance of "The Glasgow House", Buildings, 4(3) ISSN 2075-5309

Sharpe T, Porteous C, Foster J and Shearer D (2014) An assessment of environmental conditions in bedrooms of contemporary low energy houses in Scotland. Indoor and Built Environment 23 (3): 393-416.

Shearer D, Porteous C, (2012), Winter performance of 2-storey solar buffer spaces in Glasgow demonstration houses, In: Eurosun, 17-21st September 2012, Rijeka, Croatia

Wargocki, P. (2013). The effects of ventilation in homes on health. International Journal of Ventilation, 12(2), 101-118. 


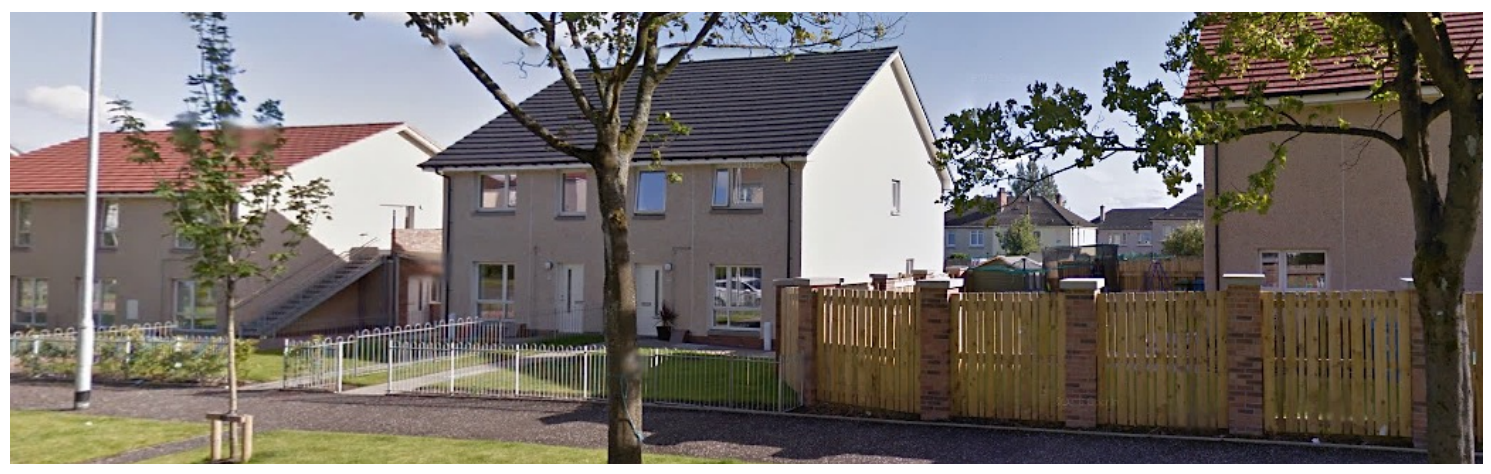

Figure 1. CS-A: Carntyne, Glasgow (55.9 Latitude, 4.2 Longitude)

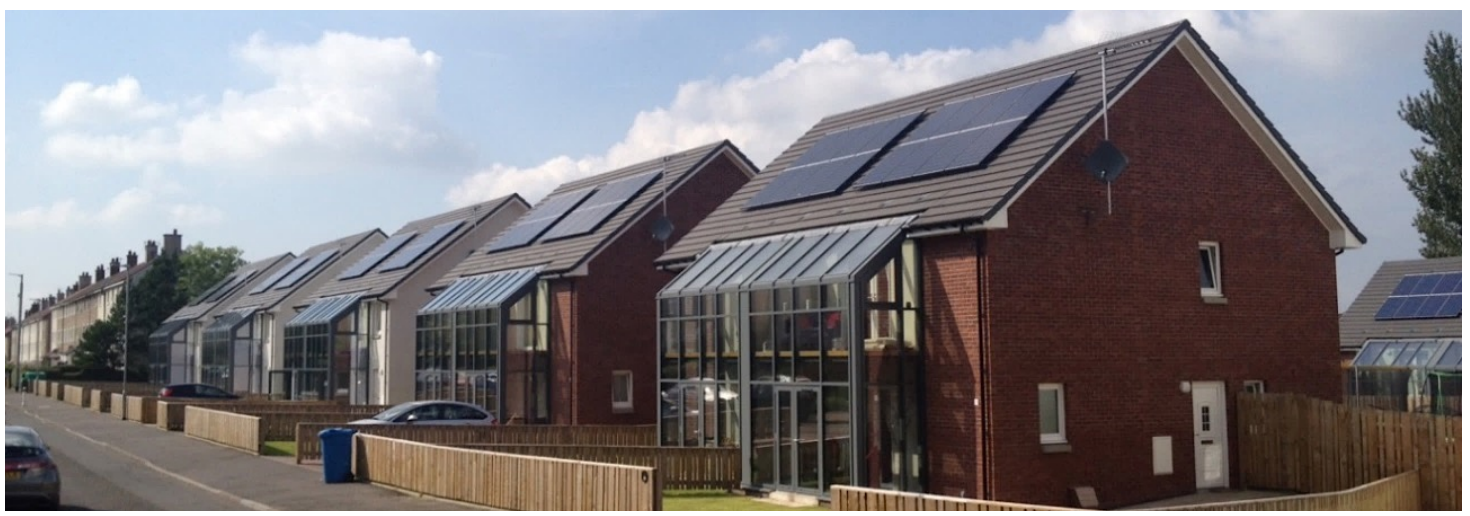

Figure 2. CS-B: Castlemilk, Glasgow (55.8 Latitude, 4.2 Longitude)

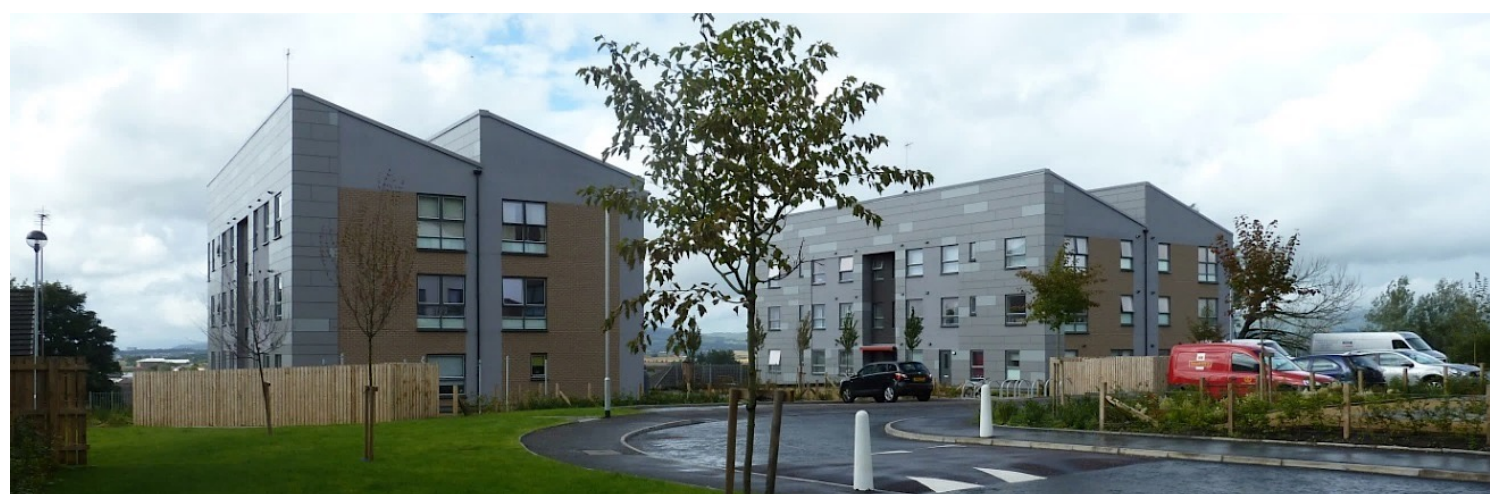

Figure 3. CS-C: Springburn, Glasgow (55.9 Latitude, 4.2 Longitude) 


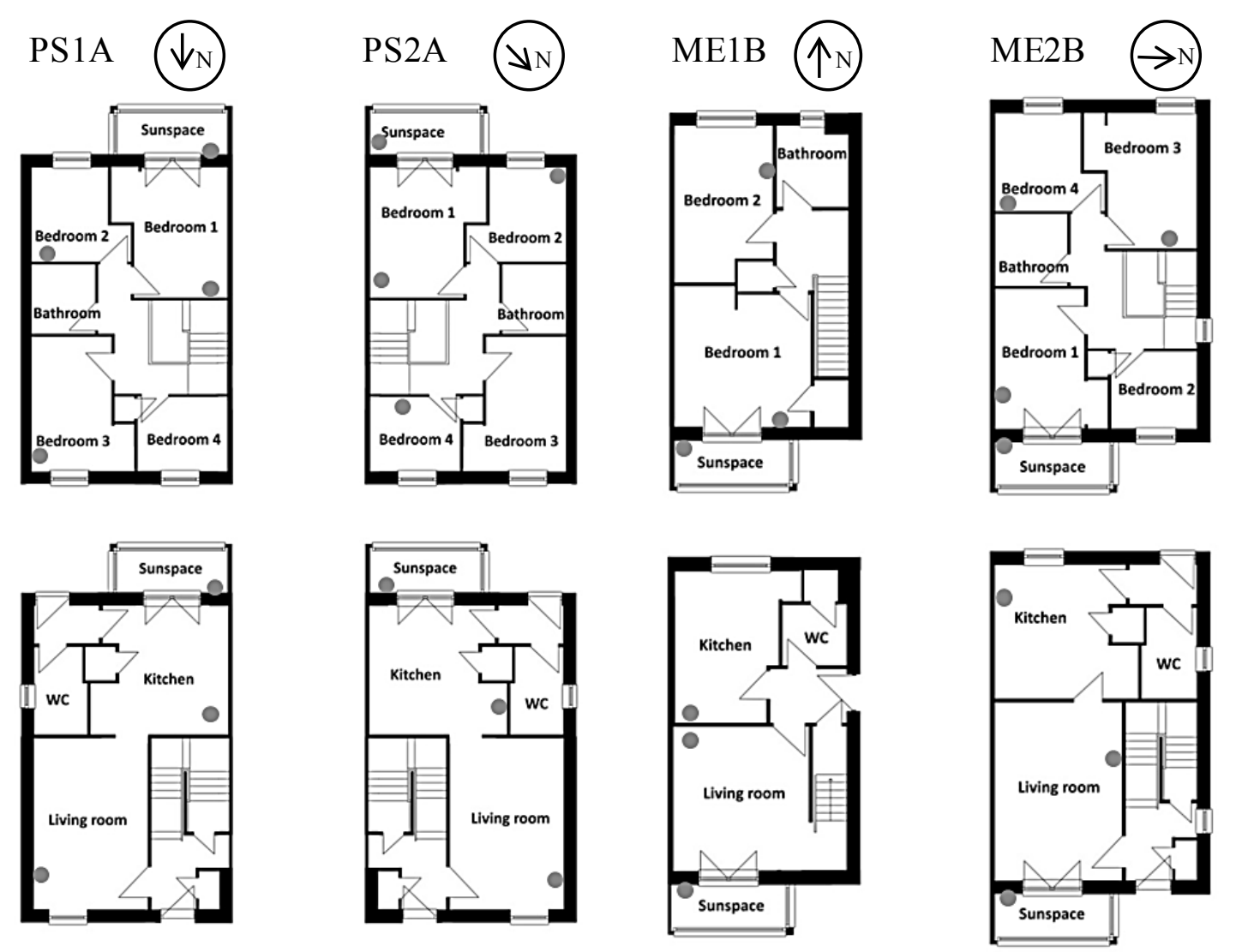

Figure 4. Floor plans and monitoring locations of dwellings at CS-A and CS-B Sensor locations 

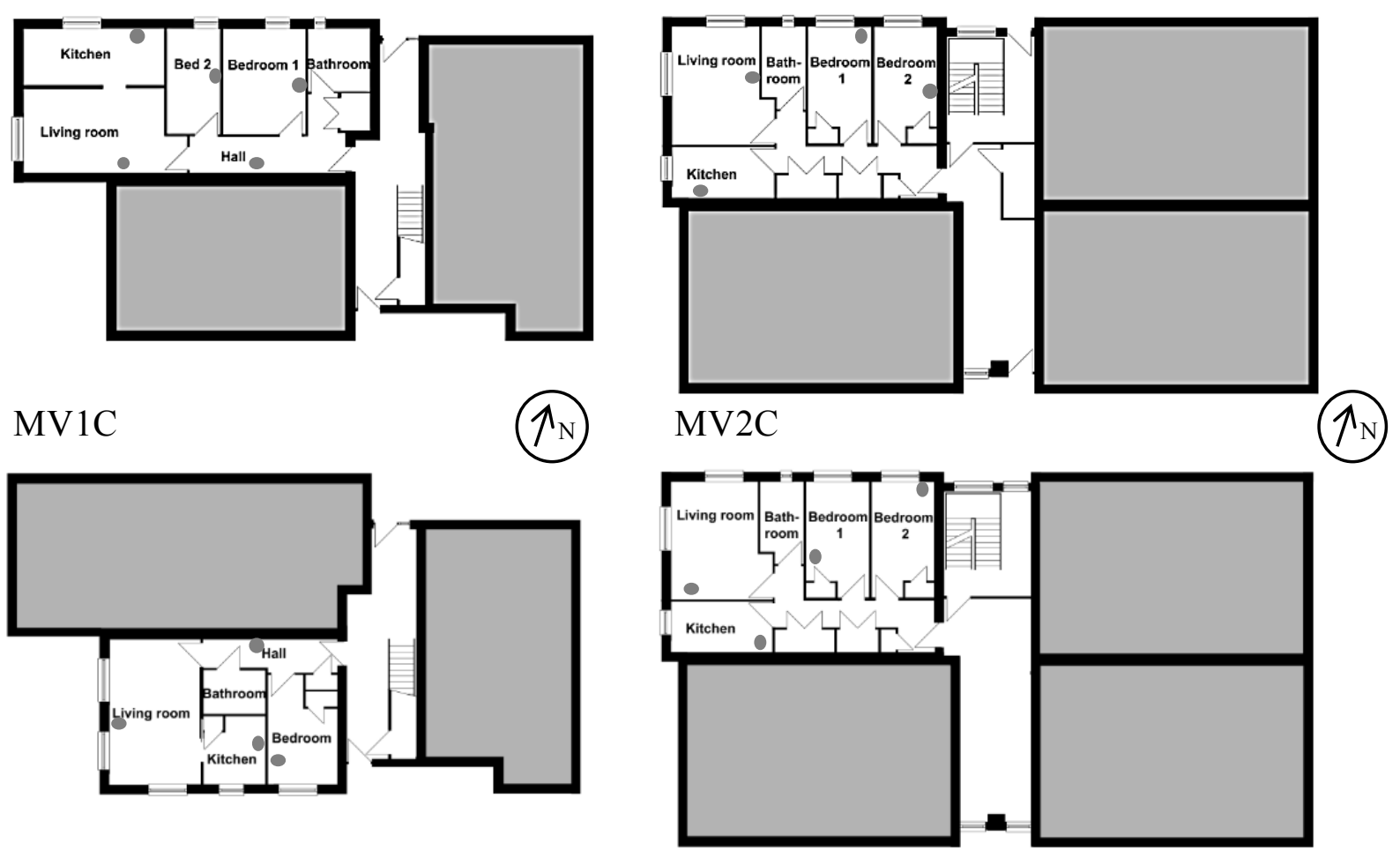

MV3C

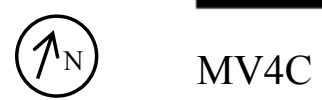

Figure 5. Floor plans and monitoring locations of dwellings at CS-C - Sensor locations 

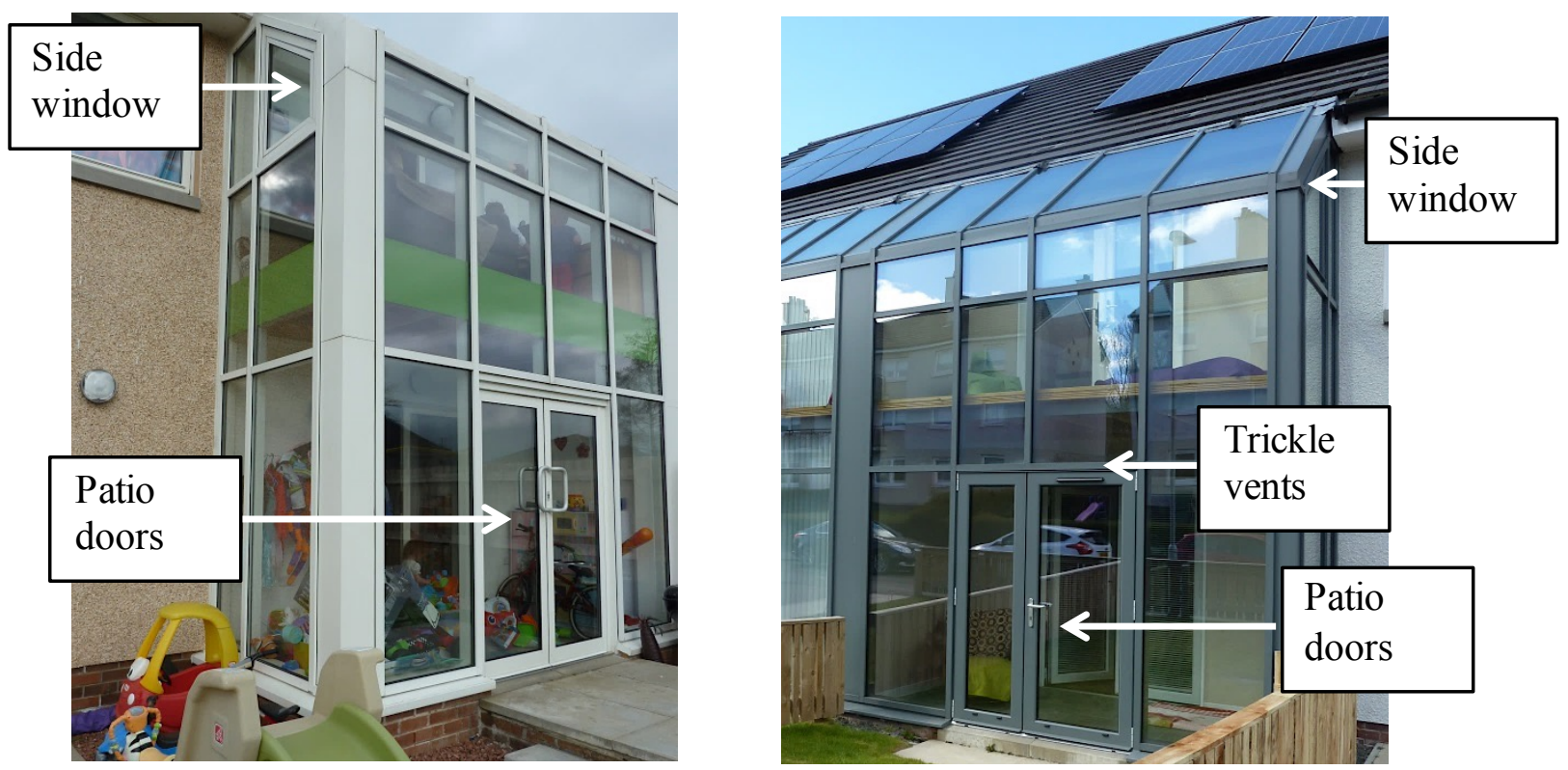

Figure 6. Air supply to sunspaces at Sites CS-A \& CS-B

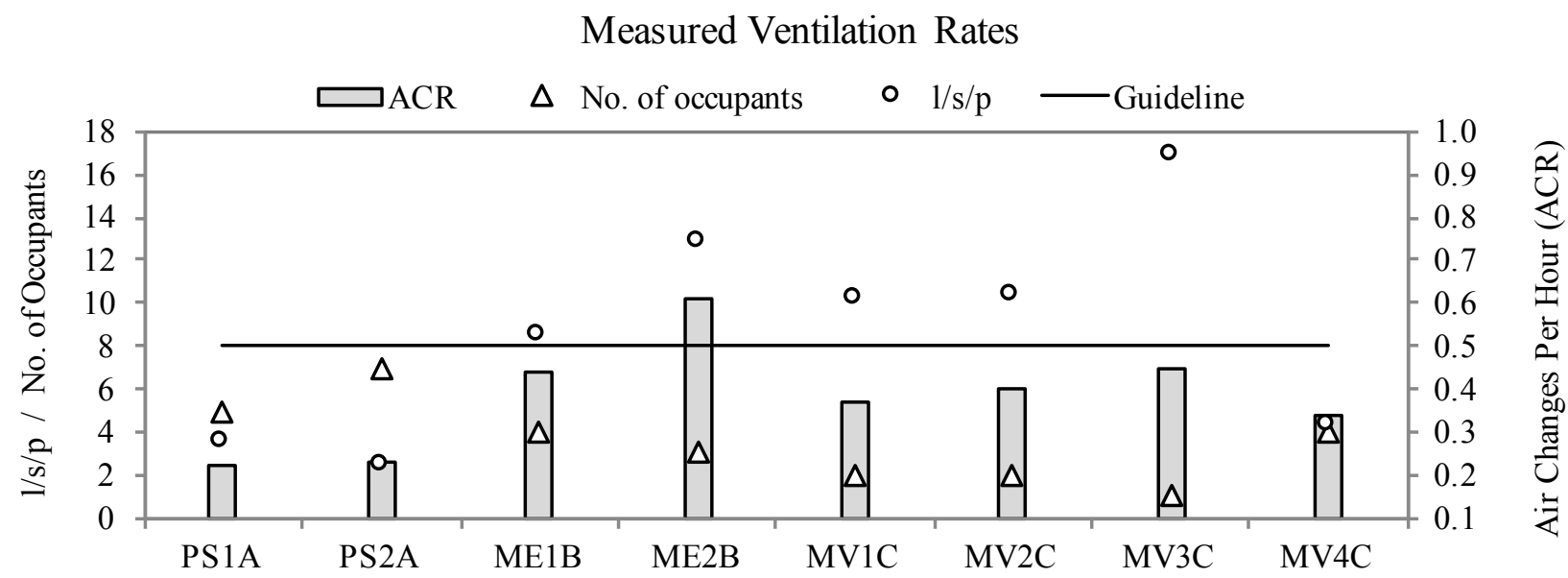

Figure 7. Measured ventilation levels in air changes per hour (ACR) and litres per second per person $(1 / \mathrm{s} / \mathrm{p})$ 
Main bedroom Carbon Dioxide Levels

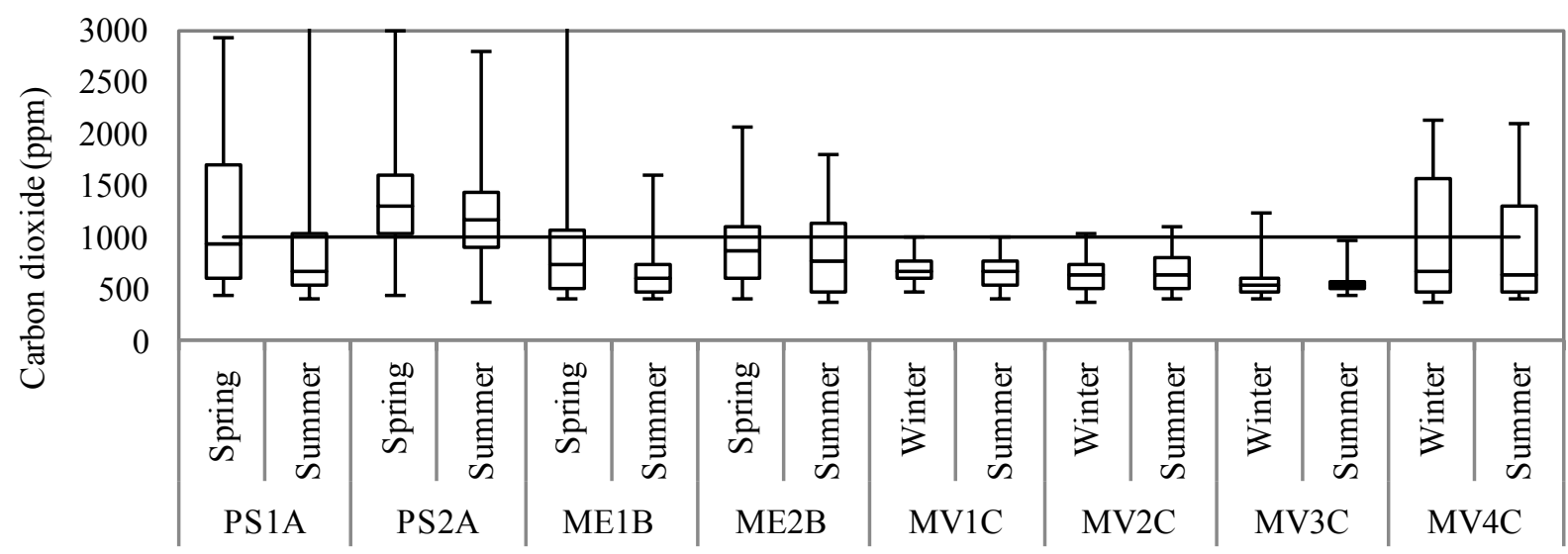

Figure 8. Bedroom carbon dioxide levels

Living Room Carbon Dioxide Levels

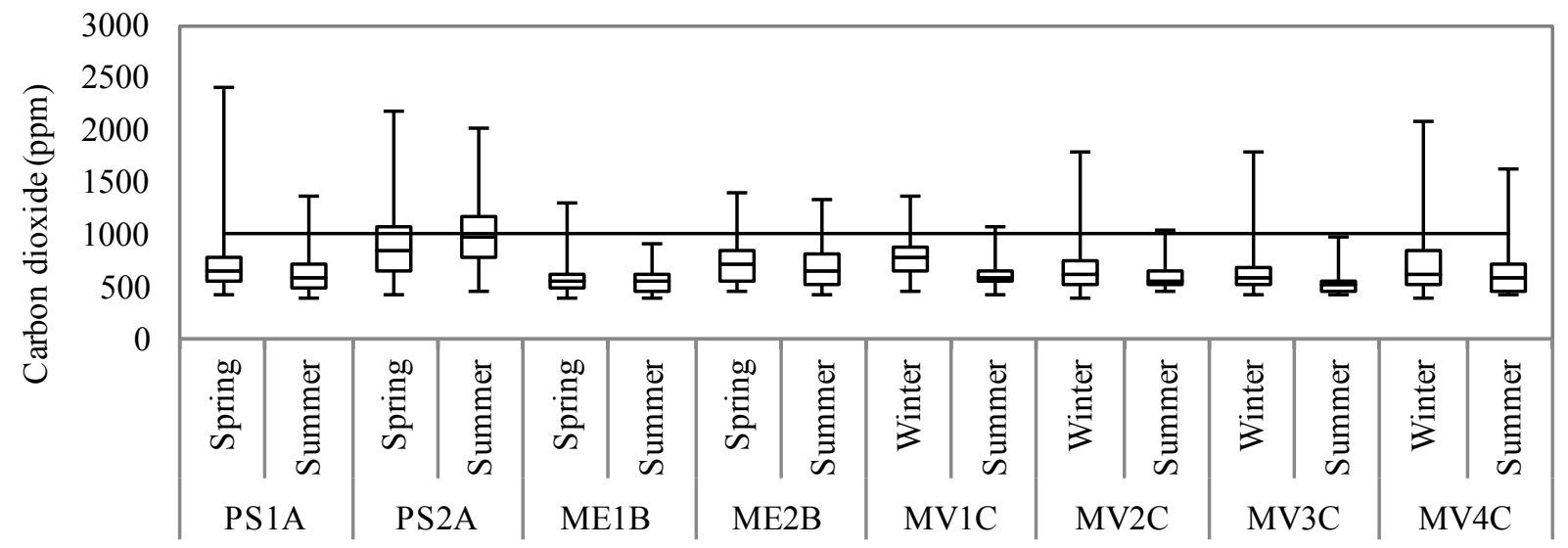

Figure 9. Living room carbon dioxide levels

Carbon dioxide levels (1st-7th April) : PS1A

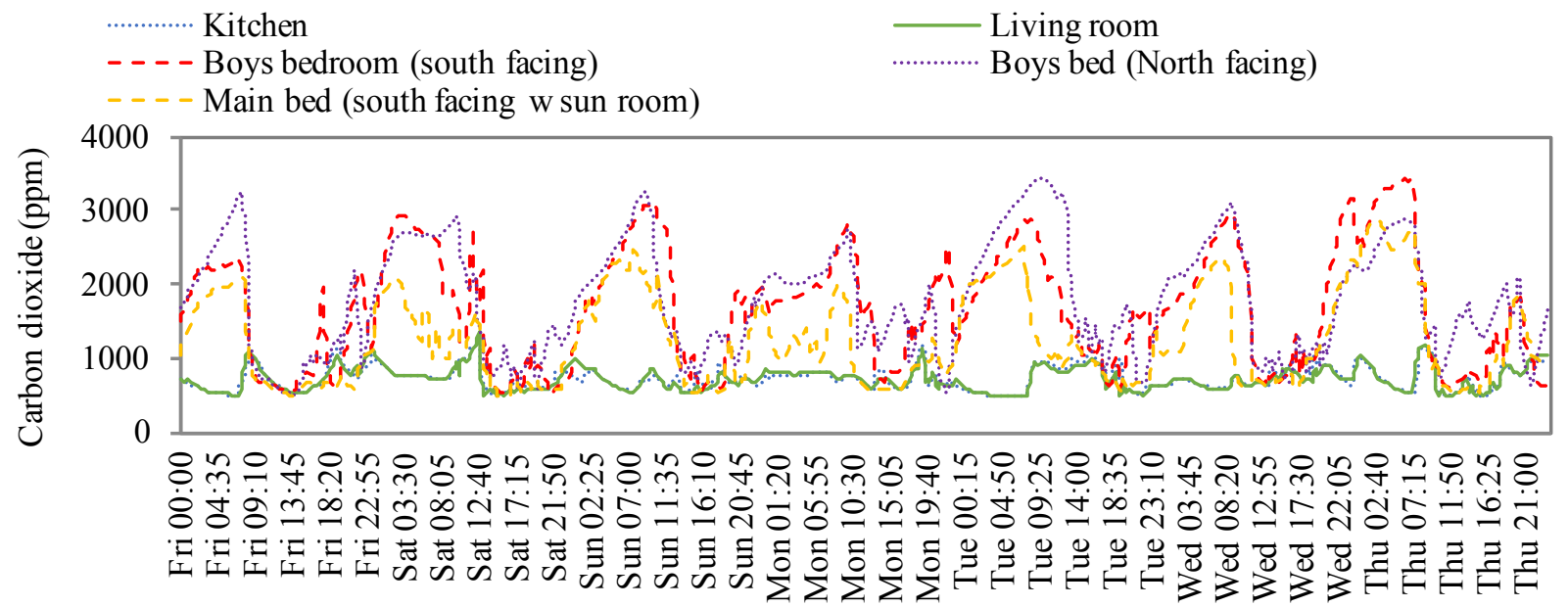

Figure 10. Carbon dioxide levels in PS1A 
Annual energy consumption $\left(\mathrm{kWh} / \mathrm{m}^{2}\right)$

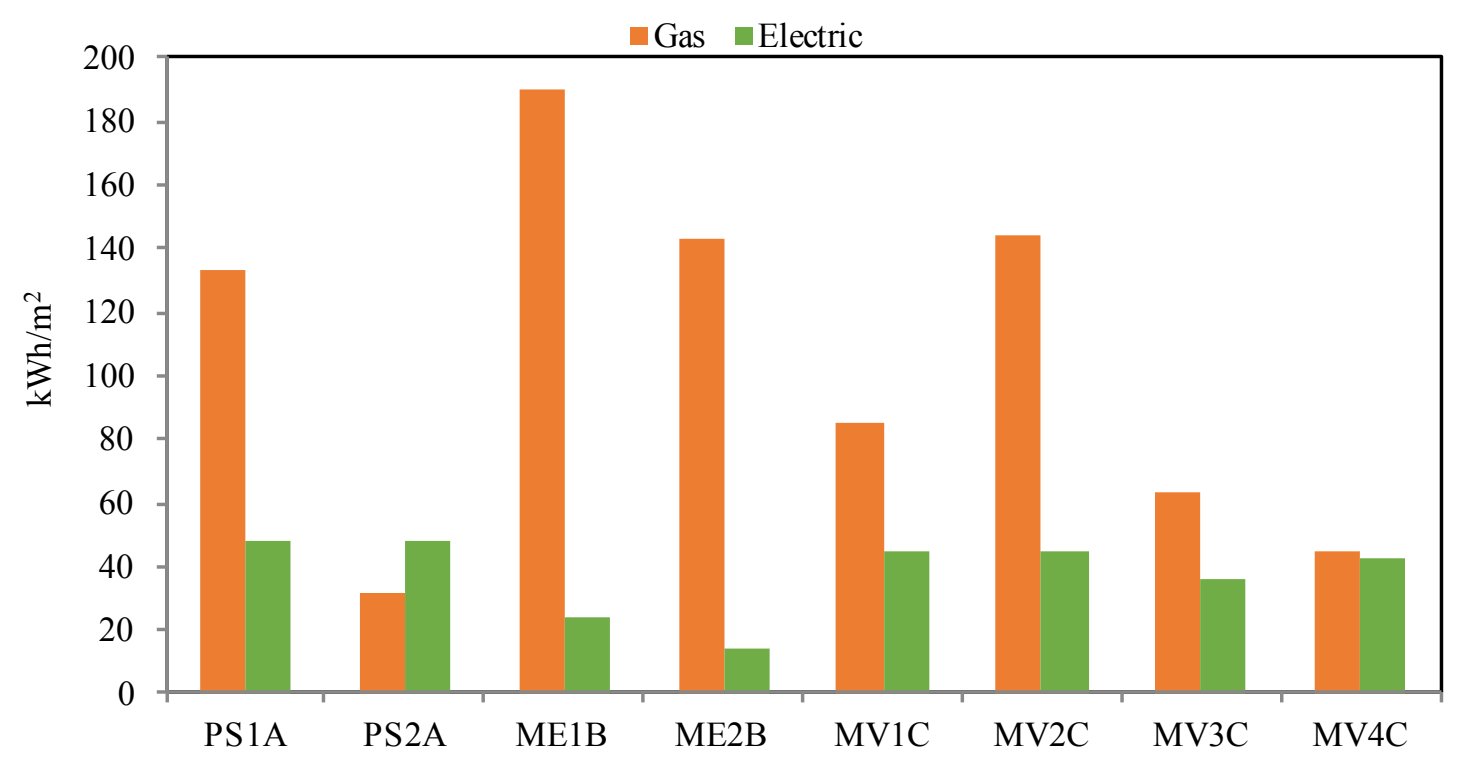

Figure 11: Annual Energy Consumption

*Extrapolated from measured data

February Weekly Temperature: MV2C

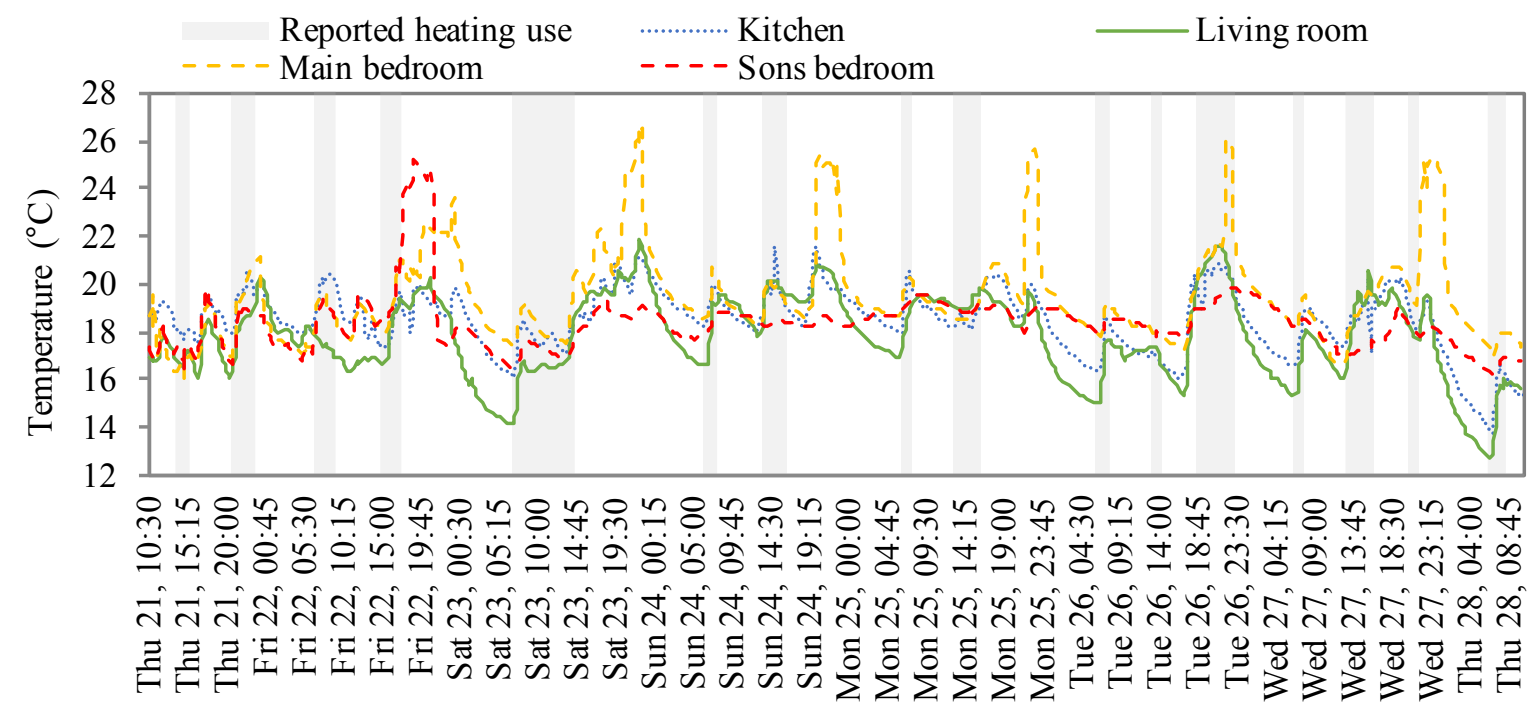

Figure 12: Weekly temperature in February (MV2C) 
Table 1. Dwelling characteristics

\begin{tabular}{lccccccccc}
\hline Code & Vent. & Site & Type & $\begin{array}{c}\text { Orient- } \\
\text { ation }\end{array}$ & $\begin{array}{c}\text { Floor } \\
\text { area }\end{array}$ & Sunspace Occupancy & $\begin{array}{c}\text { Home } \\
\text { occupied }\end{array}$ & $\begin{array}{c}\text { Airtightness } \\
\left(\mathrm{m}^{3} / \mathrm{h} / \mathrm{m}^{2}\right)\end{array}$ \\
\hline PS1A & PS & A & S & N/S & $108 \mathrm{~m}^{2}$ & Yes & 2A, 3C & Eve+w-ends & 4.76 \\
PS2A & PS & A & S & NE/SW & $107 \mathrm{~m}^{2}$ & Yes & 2A, 5C & All day & 5.60 \\
ME1B & dMEV & B & S & N/S & $107 \mathrm{~m}^{2}$ & Yes & 2A, 2C & Eve+w-ends & 5.99 \\
ME2B & dMEV & B & S & E/W & $88 \mathrm{~m}^{2}$ & Yes & $3 \mathrm{~A}$ & Eve+w-ends & 5.42 \\
MV1C & MVHR & C & GFF & N/W & $83 \mathrm{~m}^{2}$ & No & $2 \mathrm{~A}$ & All day & --- \\
MV2C & MVHR & C & GFF & N/W & $77 \mathrm{~m}^{2}$ & No & 2A & All day & 11.13 \\
MV3C & MVHR & C & GFF & S/W & $56 \mathrm{~m}^{2}$ & No & 1A & All day & --- \\
MV4C & MVHR & C & 1FF & N/W & $77 \mathrm{~m}^{2}$ & No & 2A 2C & Eve+w-ends & --- \\
\hline
\end{tabular}

PS=Passive Stack, dMEV = decentralised Mechanical Extract Ventilation, MVHR = Mechanical Ventilation with Heat Recovery; $\mathrm{S}=$ semi detached, GFF = ground floor flat. $1 \mathrm{FF}=$ First floor flat.

Table 2: Measured extract rates in dwellings with Passive Stack (PS) and Mechanical Extract Ventilation (ME)

\begin{tabular}{ccccccc}
\hline House & $\begin{array}{c}\text { House } \\
\text { volume }\end{array}$ & $\begin{array}{c}\text { Downstairs } \\
\text { bathroom }\end{array}$ & $\begin{array}{c}\text { Upstairs } \\
\text { bathroom }\end{array}$ & Kitchen & Total (1/s) & Total (ach) \\
\hline PS1A & $280 \mathrm{~m}^{3}$ & $-5.1 \mathrm{l} / \mathrm{s}$ & $-5.8 \mathrm{l} / \mathrm{s}$ & $-6.5 \mathrm{l} / \mathrm{s}$ & $17.4 \mathrm{l} / \mathrm{s}$ & $0.22 \mathrm{ach}$ \\
PS2A & $277 \mathrm{~m}^{3}$ & $-6.9 \mathrm{l} / \mathrm{s}$ & $-4.5 \mathrm{l} / \mathrm{s}$ & $-6.1 \mathrm{l} / \mathrm{s}$ & $17.5 \mathrm{l} / \mathrm{s}$ & $0.23 \mathrm{ach}$ \\
\hline ME1B & $279 \mathrm{~m}^{3}$ & $-4.21 / \mathrm{s}$ & $-5.9 \mathrm{l} / \mathrm{s}$ & $-24.1 \mathrm{l} / \mathrm{s}$ & $-34.21 / \mathrm{s}$ & $0.44 \mathrm{ach}$ \\
ME2B & $229 \mathrm{~m}^{3}$ & $-8.0 \mathrm{l} / \mathrm{s}$ & $-4.1 \mathrm{l} / \mathrm{s}$ & $-26.61 / \mathrm{s}$ & $-38.71 / \mathrm{s}$ & $0.61 \mathrm{ach}$ \\
\hline
\end{tabular}

Table 3: Measured supply and extract rates in dwellings with Mechanical Ventilation with Heat Recovery

\begin{tabular}{ccccccccc}
\hline House & $\begin{array}{c}\text { House } \\
\text { volume }\end{array}$ & Bathroom & $\begin{array}{c}\text { Living } \\
\text { room }\end{array}$ & Kitchen & Bed 1 & Bed 2 & $\begin{array}{c}\text { Total (1/s) } \\
\text { supply }\end{array}$ & $\begin{array}{c}\text { Total (1/s) } \\
\text { extract }\end{array}$ \\
\hline MV1C & $199 \mathrm{~m}^{3}$ & -7.8 & 7.6 & -11.2 & 6.6 & 7.4 & 21.6 & 19.0 \\
MV2C & $185 \mathrm{~m}^{3}$ & -9.6 & 1.8 & -11.0 & 9.4 & $*$ & ---- & 20.6 \\
MV3C & $136 \mathrm{~m}^{3}$ & -8.7 & 7.7 & -11.3 & -8.7 & $\mathrm{n} / \mathrm{a}$ & 13.7 & 20.0 \\
MV4C & $185 \mathrm{~m}^{3}$ & -11.5 & 4.2 & -10.9 & 4.8 & 3.1 & 12.1 & 22.4 \\
\hline
\end{tabular}

*Access to this room was not possible at the time of the measurements 
Table 4. Indoor Environmental Conditions in monitored rooms

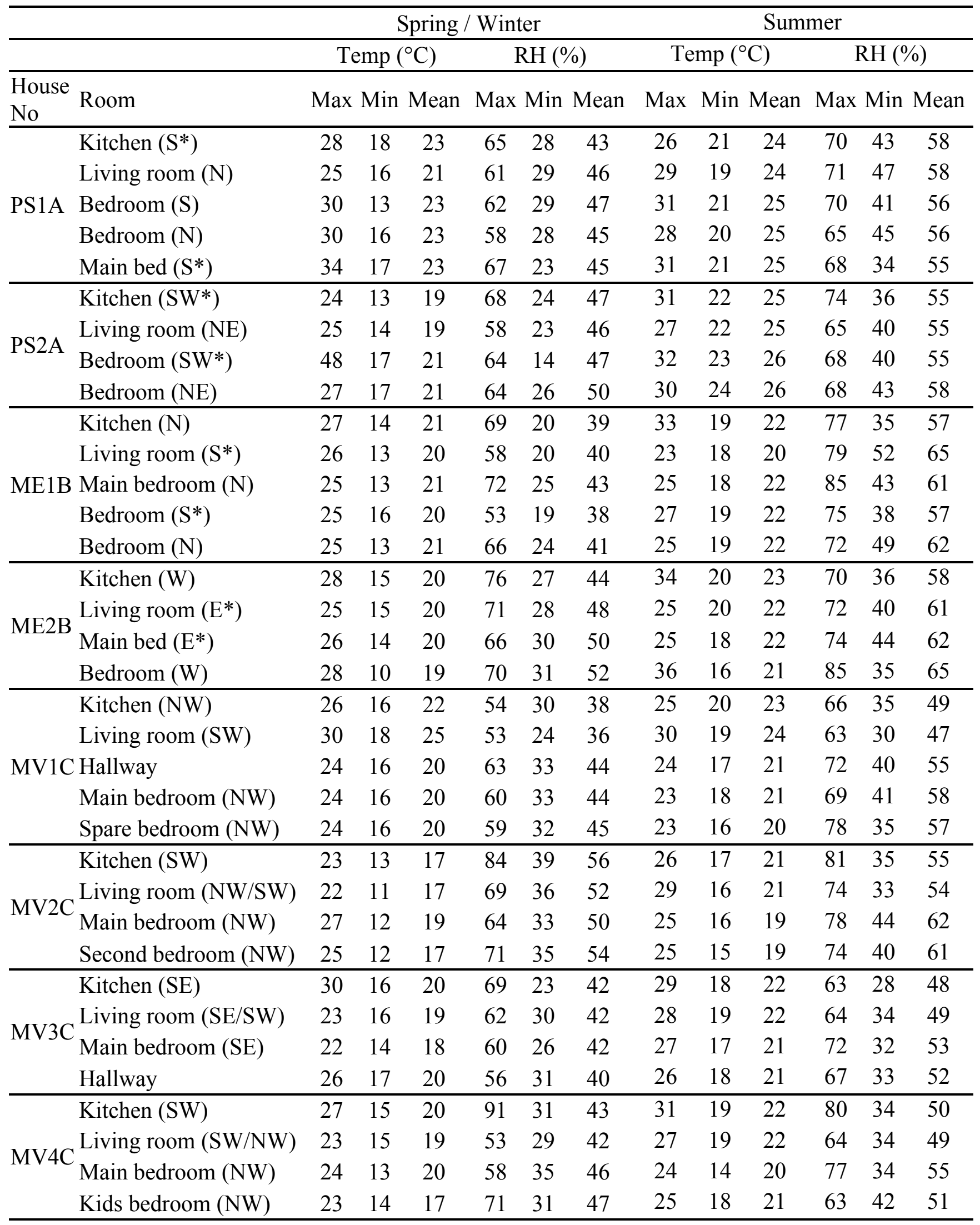

*Adjacent to the sunspace 
Table 5. Comparison of indoor conditions in sunspace with adjacent rooms

\begin{tabular}{|c|c|c|c|c|c|c|c|c|c|c|c|c|c|}
\hline & & \multicolumn{6}{|c|}{ Spring / Winter } & \multicolumn{6}{|c|}{ Summer } \\
\hline & & \multicolumn{3}{|c|}{ Temp $\left({ }^{\circ} \mathrm{C}\right)$} & \multicolumn{3}{|c|}{ RH (\%) } & \multicolumn{3}{|c|}{ Temp $\left({ }^{\circ} \mathrm{C}\right)$} & \multicolumn{3}{|c|}{ RH (\%) } \\
\hline $\begin{array}{l}\text { House } \\
\text { No }\end{array}$ & Room & Max & Min & Mean & Max & Min & Mean & Max & Min & Mean & Max & Min & Mean \\
\hline \multirow{4}{*}{ PS1A } & Downstairs sunspace & 57 & 4 & 17 & 96 & 7 & 48 & 41 & 15 & 23 & 84 & 26 & 58 \\
\hline & Adjacent kitchen & 28 & 18 & 23 & 65 & 28 & 43 & 26 & 21 & 24 & 70 & 43 & 58 \\
\hline & Upstairs sunspace & 55 & 4 & 19 & 89 & 12 & 44 & 52 & 14 & 22 & 87 & 10 & 56 \\
\hline & Adjacent bedroom & 34 & 17 & 23 & 67 & 23 & 45 & 31 & 21 & 25 & 68 & 34 & 55 \\
\hline \multirow{4}{*}{ PS2A } & Downstairs sunspace & 44 & 7 & 16 & 79 & 13 & 52 & 44 & 16 & 23 & 79 & 12 & 55 \\
\hline & Adjacent kitchen & 24 & 13 & 19 & 68 & 24 & 47 & 31 & 22 & 25 & 74 & 36 & 55 \\
\hline & Upstairs sunspace & 52 & 7 & 17 & 75 & 14 & 48 & 62 & 16 & 26 & 72 & 8 & 47 \\
\hline & Adjacent bedroom & 48 & 17 & 21 & 64 & 14 & 47 & 32 & 23 & 26 & 68 & 40 & 55 \\
\hline \multirow{4}{*}{ ME1B } & Downstairs sunspace & 33 & 7 & 19 & 69 & 14 & 42 & 33 & 17 & 22 & 69 & 31 & 55 \\
\hline & Adjacent living room & 26 & 13 & 20 & 58 & 20 & 40 & 23 & 18 & 20 & 79 & 52 & 65 \\
\hline & Upstairs sunspace & 52 & 5 & 20 & 72 & 5 & 41 & 53 & 15 & 24 & 69 & 9 & 45 \\
\hline & Adjacent bedroom & 25 & 16 & 20 & 53 & 19 & 38 & 27 & 19 & 22 & 75 & 38 & 57 \\
\hline \multirow{4}{*}{ ME2B } & Downstairs sunspace & 29 & 7 & 14 & 89 & 24 & 61 & 34 & 16 & 21 & 80 & 35 & 61 \\
\hline & Adjacent living room & 25 & 15 & 20 & 71 & 28 & 48 & 25 & 20 & 22 & 72 & 40 & 61 \\
\hline & Upstairs sunspace & 39 & 6 & 16 & 88 & 17 & 59 & 45 & 15 & 22 & 86 & 22 & 60 \\
\hline & Adjacent bedroom & 26 & 14 & 20 & 66 & 30 & 50 & 25 & 18 & 22 & 74 & 44 & 62 \\
\hline
\end{tabular}

